\title{
Measuring Specialty Indecision among Career-Decided Students
}

\author{
Mark L. Savickas \\ Northeastern Ohio Universities College of Medicine \\ Dale E. Alexander \\ College of Medicine, The Ohio State University
}

Samuel H. Osipow

The Ohio State University

AND

FredRIC M. WolF

Medical School, University of Michigan

\begin{abstract}
Increasing numbers of career-decided students in professional and graduate schools have difficulty choosing a specialty. To begin to examine this problem, a measure of specialty indecision was devised by changing the Career Decision Scale items to deal with specialty indecision rather than career indecision. The scale was then administered to 567 medical students along with measures of vocational development and exploratory behavior. Initial evaluation of the psychometric properties of the Specialty Indecision Scale indicate that it is internally consistent, relates more to specialty choice than to career choice, and inversely relates to both vocational development and exploratory behavior. A factor analysis of the scale items extracted four factors that reflect cognitive, conative, criterion, and implementation restraints on the decision-making process. The Specialty Indecision Scale seems to be useful for diagnostic and research purposes in the study and treatment of specialty indecision. 1985 Academic Press, Inc.
\end{abstract}

People preparing for a professional career have more difficulty choosing a specialty as occupational roles become more specialized. Students in

The authors thank J. Hutchison Williams, M.D., Associate Dean of Student Affairs at The Ohio State University College of Medicine, for facilitating this study. Requests for reprints should be sent to Mark L. Savickas, Behavioral Sciences Program, NEOUCOM, Rootstown, OH 44272. 
professional and graduate schools have chosen a career and are already implementing their career choice yet indecision regarding which specialty to choose within their career field often continues. For example, specialty indecision among medical students and physicians is well documented. Physicians in training must choose from among 63 specialty and subspecialty alternatives. Some medical students choose a specialty early and perhaps easily, but the majority report difficulty in choosing a specialty (Huebner, Royer, \& Moore, 1981). Longitudinal studies indicate that between 60 and $75 \%$ of medical students change their specialty choice during medical school (Markert, 1983), 20\% of physicians in residency training switch to unrelated specialties (Weisman, Levine, Steinwachs, \& Chase, 1980), and $16 \%$ of physicians in practice change their specialty identification (Holden \& Levit, 1978). Although we do not know the extent of specialty indecision in other professions such as engineering, nursing, and social work, we can assume that many students who are preparing for professional careers have difficulty in choosing a specialty.

Most research related to specialty indecision deals with specialty choice rather than the specialty decision-making process. Typically these studies match specialties to personality traits or demographic characteristics in trying to identify the type of people who choose each specialty. Unfortunately, this typological approach, which has been so successful in describing career types, has produced inconsistent and unreplicated descriptions of career subtypes, that is, specialty types (Anderson, 1975; Bureau of Health Resources Development, 1974). In short, the matching model works better in distinguishing between people in different career fields than in distinguishing between people in the same career field (Cochran, Vinitsky, \& Warren, 1974; Holland \& Holland, 1977). The problem of specialty indecision would be better addressed by focusing less on specialty choice and more on specialty decision making and the antecedents of specialty indecision.

To address specialty indecision, researchers and practitioners need a measure of the construct. Conceivably, existing career indecision scales could be changed to measure specialty indecision. Although the scope of choice content is limited to one field, some of the same restraints that impede career decision making may also impede specialty decision making. The following report describes how the Career Decision Scale (Osipow, Carney, Winer, Yanico, \& Koschier, 1976), the best available measure of career indecision (Rogers \& Westbrook, 1983), was modified to devise a measure of specialty indecision and presents initial validity evidence for this new scale.

The present study sought to determine how well the Specialty Indecision Scale (SIS) meets six validity criteria. First, its items should have high domain reliability, constitute a general factor, and moderately relate to the total score, because the scale purports to measure degree of specialty 
indecision. Second, the items should form group factors that represent different types of restraints on specialty decision making, because the items state conceptually distinct antecedents of specialty indecision that can be experienced simultaneously (Hartman, Utz, \& Farnum, 1979; Osipow, Carney, \& Barak, 1976). Third, each item should inversely relate to certainty of specialty choice because the items state antecedents that can impede decision making. Fourth, the scale should show discriminant validity by relating more to certainty of specialty choice than to certainty of career choice. Fifth, the SIS total score should inversely relate to both chronological age and level of training because indecision decreases with age and experience (Crites, 1969). And sixth, the SIS total score should inversely relate to measures of exploratory behavior and vocational development (Jepsen \& Prediger, 1981).

\section{METHOD}

\section{Specialty Indecision Scale}

Changing the Career Decision Scale (with its author's permission') into a specialty decision scale was more complicated than just adapting the Career Decision Scale (CDS) to measure career indecision among graduate students (Hartman et al., 1979). Conceptually, this specialty decision scale is not an adaptation of the CDS for a new population; it is a different instrument. A specialty decision scale cannot deal directly with career decision making. In fact, it must hold career choice constant while measuring specialty decision making among alternative occupational roles within the chosen career field. Psychometrically, this requires that a specialty decision scale relate more to specialty choice certainty than to career choice. Yet, a specialty decision scale must also relate to career choice certainty because, in some students, specialty indecision reflects a more basic career indecision.

Changing the CDS items into SIS items was straightforward. The original CDS begins with a certainty of career choice item and a certainty of educational major item. The educational choice item was changed to address certainty of specialty choice. The rest of the CDS includes 16 items, each of which states a conceptually distinct antecedent of career indecision. The antecedents of indecision stated in the 16 items came from programmatic research on indecision among college undergraduates. Each antecedent potentially reduces a person's ability to make a career choice. Furthermore, a person may simultaneously experience more than one of these distinct antecedents. Students respond to each item using

\footnotetext{
'Requests for permission to make any modifications of the Career Decision Scale or to use this specialty modification should be sent to Samuel $\mathrm{H}$. Osipow, 1885 Neil Avenue Mall, Columbus, $\mathrm{OH} 43210$.
} 
a Likert scale that ranges from 1 (Not at all like me) to 4 (Exactly like $m e$ ). The total score for the 16 items indicates degree of indecision.

To modify items for the SIS, the word "specialty" was substituted for the words "career" and "occupation" in 13 of the 16 CDS items. Item 5 was changed from "I know I will have to go to work" to "I know I will have to choose a specialty." Item 12 was changed from "I know what I'd like to major in" to "I know which rotation I'll like the best." Item 18 was changed from "I think I know what to major in" to "I think I know what I want to specialize in." The changes in item wording yielded a specialty decision scale with face and content validity. Because the item revisions were so modest, the revised scale is not presented here. The original CDS items appear in Osipow, Carney, and Barak (1976) and in Osipow (1980). Item names that summarize the meaning of each SIS item appear in Table 1.

\section{Measurement of the Criterion Variables}

Degree and focus of vocational development were measured with the Medical Career Development Inventory (MCDI; Savickas, 1984). Its total

TABLE 1

Correlations of Specialty Indecision Scale Items with Rotated Factors

\begin{tabular}{|c|c|c|c|c|}
\hline Specialty Indecision Scale item names & Factor 1 & Factor 2 & Factor 3 & Factor 4 \\
\hline $\begin{array}{l}\text { First choice not possible because of lack of } \\
\text { skills or opportunity (3) }\end{array}$ & & .42 & & \\
\hline Several specialties equally appeal to me (4) & .63 & & & \\
\hline No specialties appeal (5) & & .51 & & \\
\hline $\begin{array}{l}\text { A particular specialty I like is against the } \\
\text { wishes of someone important (6) }\end{array}$ & & & .41 & \\
\hline Feel lost when I think about it (7) & $(.43)$ & .54 & & \\
\hline $\begin{array}{l}\text { Feel discouraged because choosing seems } \\
\text { "iffy" (8) }\end{array}$ & & .51 & & \\
\hline $\begin{array}{l}\text { Learned my choice was not possible for } \\
\text { me (9) }\end{array}$ & & .36 & $(.33)$ & \\
\hline $\begin{array}{l}\text { Need to be absolutely certain that my } \\
\text { choice is the "right" one (10) }\end{array}$ & & (.38) & .43 & \\
\hline $\begin{array}{l}\text { Making a specialty decision bothers me } \\
\text { (11) }\end{array}$ & & & .41 & \\
\hline Not sure the specialty can satisfy me (12) & & & .51 & \\
\hline Unaware of my abilities (13) & .62 & $(.38)$ & & \\
\hline Unaware of my interests (14) & .65 & $(.42)$ & & \\
\hline Many things of interest (15) & .64 & & & \\
\hline $\begin{array}{l}\text { Have decided but I am not certain how to } \\
\text { implement (16) }\end{array}$ & & & & .64 \\
\hline Need more information (17) & .79 & & & \\
\hline Need support (18) & & & & .63 \\
\hline Eigenroots & 4.60 & 1.74 & 1.46 & 1.15 \\
\hline$\%$ total variance & 28.7 & 10.9 & 9.1 & 7.2 \\
\hline$\%$ common variance & 59.8 & 17.9 & 13.1 & 9.2 \\
\hline
\end{tabular}


score indexes degree of development and its seven scale scores indicate focus of development within the exploration stage of a physician's career. The first six scales measure crystallization, specification, and implementation of a career choice and a specialty choice, respectively. The seventh scale measures stabilizing in a practice position. MCDI scales IV and $V$ were of particular interest in the present study because they measure specialty crystallization and specification. Scale IV, Crystallizing Specialty Preferences, measures the coping behaviors that deal with the vocational development task of forming a clear picture of one's specialty interests, abilities, and goals. Scale V, Specifying a Specialty Choice, measures the coping behaviors that deal with the vocational development task of choosing a specialty. The MCDI consists of 35 items, 5 for each task scale. Students responded to the items on a 5-point Likert scale that ranged from 5 (I have already done this) to 1 (I have not yet thought much about it). Savickas (1984) presented support for the content, construct, and criterion-related validity of the MCDI and reported a Cronbach coefficient $\alpha$ of .93 for the inventory and coefficients ranging from .73 to .91 with a median of .81 for the seven scales. In the present study, the $\alpha$ coefficients for the inventory and scales IV and V were .92, .75, and .93 , respectively.

Exploratory behavior was measured with a six-item self-report scale devised for the present study. The scale asks students to estimate how frequently they have discussed their questions and concerns about specialty choice with close friends, family members, fellow medical students, residents on clerkship rotations, medical school faculty, and practicing physicians. Students responded to each item on a 5-point Likert scale that ranged from (1) never to (5) frequently. Summing the responses to the six items produces a total score. In the present study, the scale had a Cronbach coefficient $\alpha$ of .71.

\section{Subjects and Procedures}

Medical students were selected as the subjects for this test of the SIS's validity because they are a group of career-decided students who have difficulty in making specialty choices. A mail survey patterned after Dillman's (1978) total design method was used to collect the data. The three scales and a demographic questionnaire were placed in the campus mailboxes of all 835 students enrolled in a state supported medical school located in the midwest. Of the 835 mailings, 617 (74\%) students returned their questionnaires; $567(68 \%)$ students produced a complete set of usable data. The 567 students who constituted the sample had a mean age of 24.56 years with a standard deviation of 2.61 years. They were predominantly male $(77.6 \%)$ and white $(93.1 \%)$. Two hundred students were in Year 1 basic sciences, 182 students were in Year 2 preclinical studies, 64 students were in Year 3 clerkships, and 116 students were 
in Year 4 electives. The return rates for the four years were $78,77,55$, and $52 \%$.

\section{Data Analysis}

Descriptive statistics for each variable and Pearson product-moment correlation coefficients between all the variables were computed. Alpha factor analysis was performed on the 16 SIS items. Preliminary analyses indicated that SIS scores do not reflect sex differences. The correlation of sex with career choice certainty, specialty choice certainty, and degree of indecision ranged from -.05 to .02 . Therefore, separate analyses for each sex were unnecessary.

\section{RESULTS}

Alpha factor analysis of the item intercorrelation matrix ${ }^{2}$ extracted four factors with eigenroots greater than one. The four factors accounted for $56 \%$ of the total variance. The first factor appeared to be a general factor. It accounted for more than half of the common variance. The mean correlation between the items and the first factor was .48; only two items loaded below .30 (viz., item $16, r=.19$; item $18, r=.28$ ). Combined with an average item intercorrelation of .42 , the high firstfactor concentration and substantial item loadings form a strong case (Comrey, 1973, p. 105) for the presence of a general factor in the SIS.

Consistent with the concentration of item variance in a general factor, the items had a Cronbach coefficient $\alpha$ of .82. This index of homogeneity and first-factor generalizability indicated sufficient internal consistency and domain reliability to justify reporting a total score for the 16 SIS items.

Sufficient residual correlations remained after removal of the general factor to produce three more factors with positive generalizability. The extracted factors were rotated to interpret the underlying factor constructs. Equamax rotation broke apart the general factor and spread the extracted variance evenly across the group factors. All four extracted factors with eigenroots exceeding one were rotated so four derived factors resulted. Table 1 reports the substantive correlations $(>.30)$ of the items to the group factors. Five items $(7,9,10,13$, and 14) correlated with two factors; the lower correlation of each pair is bracketed in Table 1 .

Factor I, labeled Cognitive Restraints, includes five antecedents that describe information deficits. Three items state a need for more information about the specialties or one's interests and abilities. Two other items describe an approach-approach problem which may be resolved by more information about alternatives with equal appeal or about one's interests and abilities. Factor II, labeled Conative Restraints, includes five an-

\footnotetext{
${ }^{2}$ The item intercorrelation matrix is available from the first author.
} 
tecedents that probably decrease motivation to participate in the specialty decision-making process. Two items describe feeling lost or discouraged about making a choice. Two items express the impossibility of choosing the preferred specialty. One item states that the alternative choices lack appeal. Each of these five antecedents can demoralize students' decisional efforts. Factor III, labeled Criterion Restraints, includes four items that state excessive standards for a choice to meet. The right choice is described as one that seems ideal, guarantees future satisfaction, pleases other people, or is made quickly. Applying such criteria to a choice probably hinders the decision-making process. Factor IV, labeled Implementation Restraints, is marginally determined. It includes only two items, the same two items that did not load on the general factor. Nevertheless, the factor is coherent. Neither item states an antecedent of indecision. Instead, both items state that a choice has been made but question how to effect it; specifically, what to do next (item 16) and need for support in doing it (item 18).

The fact that 5 of the 16 items loaded on two factors can be interpreted using the factor constructs. In reading each of the 5 items, it is easy to understand why they loaded on the two factors which they did. For example, item 7 loaded on both the conative and cognitive factors. The item reads, "Until now, I haven't given much thought to choosing a specialty. I feel lost when I think about it because I haven't had many experiences in making decisions on my own and I don't have enough information to make a decision right now." The feeling lost and decisional inexperience elements probably account for the items' higher loading on the conative factor (.54), whereas the information element probably explains its lower yet still substantive loading on the cognitive factor $(.43)$.

Table 2 reports the intercorrelation among the variables. Degree of indecision inversely related to career choice certainty $(r=-.33, p<$ $.001)$ and to specialty choice certainty $(r=-.65, p<.001)$. Moreover, all 16 items inversely related to specialty choice certainty and career choice certainty. All items except item $16(r=-.08)$ inversely related to specialty choice certainty at less than the .05 level of significance.

As shown in Table 2, career choice certainty and specialty choice certainty both related to degree of vocational development, exploration, and specification task coping. Indecision inversely related to degree of vocational development $(r=-.58, p<.001)$. The correlation of indecision with the seven vocational tasks measured by the MCDI ranged from $-.20(p<.001)$ to $-.59(p<.001)$ with a mean of $-.43(p<.001)$. Indecision associated most strongly with the task of specifying a specialty choice $(r=-.59, p<.001)$. Degree of indecision weakly related to the exploration score $(r=-.16, p<.01)$. The six exploration items varied widely in relation to indecision. Indecision insignificantly related to four items ( $r$ 's from -.08 to .01 ), but indecision significantly related to ex- 


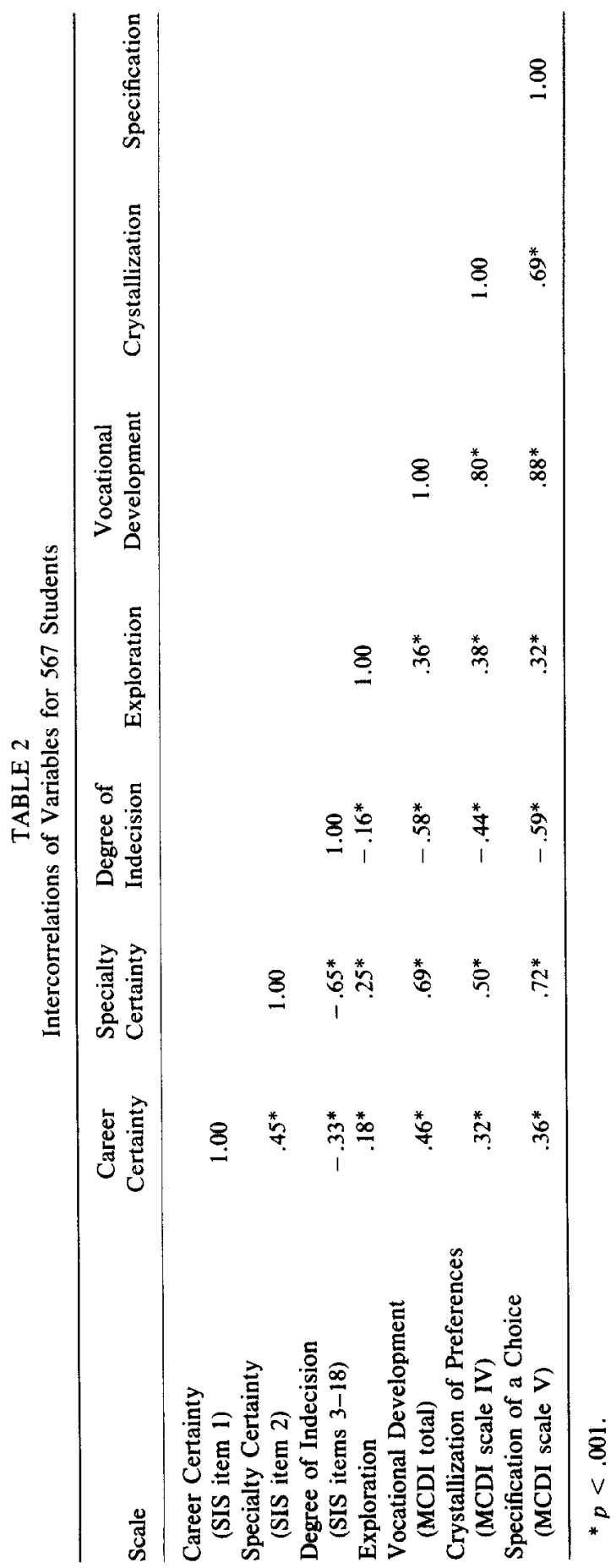


ploration with faculty $(r=-.28, p<.001)$ and with residents $(r=$ $-.25, p<.001$ ).

Mean scores for specialty choice certainty increased whereas mean scores for degree of indecision decreased across the 4 years of training (see Table 3 ). Age significantly related to specialty choice certainty ( $r$ $=.21, p<.001)$ and to degree of indecision $(r=-.21, p<.001)$ but not to career choice certainty $(r=.06)$.

\section{DISCUSSION}

Based on the item intercorrelations and the factor analysis, it may be concluded that the SIS items contribute both unique and common variance to the measurement of indecision. Each item assessed a specific antecedent of indecision as well as interrelated with other items to constitute a general factor with four group factors. The general factor indicates that the scale measures a single construct, presumably specialty indecision, with some degree of unity and coherence. The group factors indicate that the items do not measure exactly the same aspects of indecision but rather assess four different types of restraints that impede the specialty decision-making process. In other words, the scale measures a construct that is statistically homogeneous yet psychologically complex.

The four factors identified as types of impediments to specialty decision making were cognitive, conative, criterion, and implementation restraints. However, the results indicated that the implementation factor (viz., items 16 and 18) was marginally determined. Previously, Osipow, Carney, and Barak (1976) questioned whether item 16 belongs in the CDS because in their study it related positively to career choice certainty. Based on the present study, we think that implementation items probably should be removed from the SIS. Choice denotes arriving at a solution that ends uncertainty. Deciding on a choice is distinct from the course of action that implements that choice (Crites, 1969, p. 129). Therefore, decision scales such as the CDS and SIS do not need implementation items to comprehensively measure decisional status. On the contrary, implementation items only lower the homogeneity of a decision scale and decrease its validity. If there is a need to measure barriers that thwart choice implementation, then a separate scale can be devised.

The Pearson product-moment correlations show that degree of indecision related to specialty certainty more than it related to career certainty. Indecision shared almost four times more common variance with specialty certainty $(42 \%)$ than with career certainty $(11 \%)$. The fact that the SIS total score and all 16 items inversely related to specialty choice certainty supports the construct validity of the SIS. Additional support for its construct validity comes from the association of indecision with chronological age and from the monotonic decrease in total scores for students with more years in medical school. 


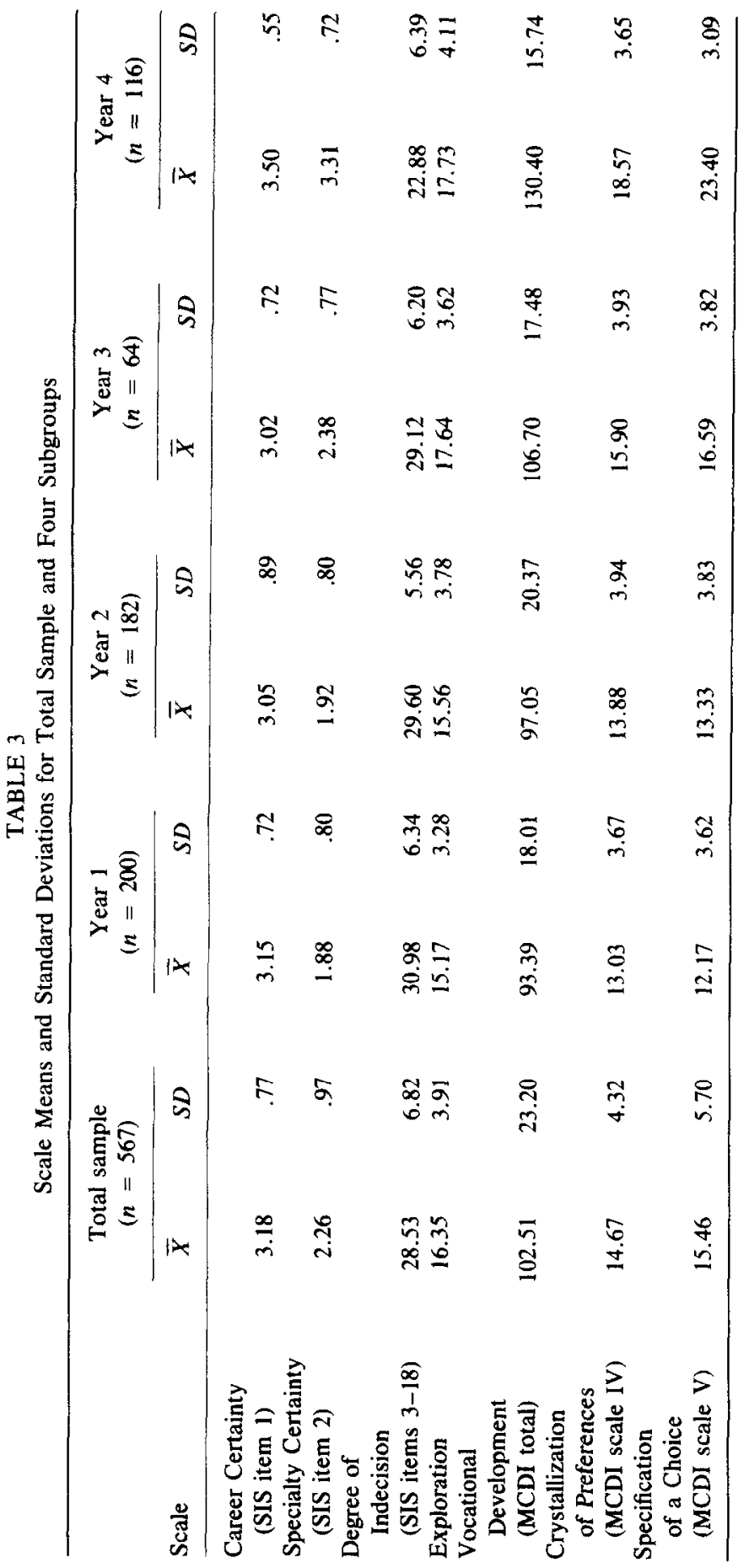


Initial support for the criterion-related validity of the SIS comes from its association with degree of vocational development $(r=-.58, p<$ $.001)$. Students who were coping with tasks further along the continuum of vocational development reported less specialty indecision. In addition, students who had focused more on the task of specifying a specialty choice reported less indecision $(r=-.59, p<.001)$. Moreover, students who had engaged in more exploration as part of the decisional process, especially by talking with residents and faculty, were less indecisive.

In sum, the modification of the Career Decision Scale seems to have produced a valid measure of specialty indecision. However, the fact that the validity data comes from a sample composed of students training for one profession in a single school limits the interpretation and generalizability of this conclusion. We need to replicate these findings with other samples of medical students and to extend these findings to students in different graduate and professional training programs. The SIS is ready to use with other professional groups because all of its items except one are general, not specific to one profession. Item 12 refers to clerkship rotations that are unique to student-physicians. On reflection, it seems that this item should state "I know which topics I like to study, but I don't know what specialties it can lead to that would satisfy me" instead of reading "I know which rotation I like best, but . . . ." It would be useful to make this change in item 12 and then study the validity and utility of the SIS with students in nursing and social work. These two professions have had to specialize in reaction to specialized medicine (Palmiere, 1981). The SIS should also be studied with engineering and psychology students because their specialties are clearly defined. At this time, the SIS may not be as useful to law students because its specialities, other than patent law, are not as clearly defined. However, professions such as law and accounting may develop more clearly defined specialties in response to technical developments and entreprenuerial practice. For instance, the American Bar Association (1983) is proposing model legislation that asks states to recognize 24 specialties within law.

In addition to validating the SIS with students in different professions, we need to cross validate the four types of restraints on specialty decision making and examine the convergent and discriminant validity of SIS subscales. If the SIS receives additional validity support from future studies, then it could be useful to practitioners and researchers who want to measure or study specialty indecision.

\section{REFERENCES}

American Bar Association. (1983). Handbook on specialization. Chicago, IL: Author.

Anderson, R. B. (1975). Choosing a medical specialty: A critique of the literature in light of "curious findings." Journal of Health and Social Behavior, 16, 152-162.

Bureau of Health Resources Development (1974). Medical specialty selection: A review and bibliography (DHEW Publication No. HRA 75-8). Washington, DC: U.S. Gov. Printing Office. 
Cochran, D. J., Vinitsky, M. H., \& Warren, P. M. (1974). Career counseling: Beyond "test and tell." Personnel and Guidance Journal, 52, 659-664.

Comrey, A. L. (1973). A first course in factor analysis. New York: Academic Press.

Crites, J. O. (1969). Vocational psychology. New York: McGraw-Hill.

Dillman, D. A. (1978). Mail and telephone surveys: The total design method. New York: Wiley.

Hartman, B. W., Utz, P. W., \& Farnum, S. O. (1979). Examining the reliability and validity of an adapted scale of educational-vocational undecidedness in a sample of graduate students. Journal of Vocational Behavior, 15, 224-230.

Holden, W. D., \& Levit, E. J. (1978). Migration of physicians from one specialty to another. Journal of the American Medical Association, 239, 205-209.

Holland, J. L., \& Holland, J. E. (1977). Distributions of personalities within occupations and fields of study. Vocational Guidance Quarterly, 25, 226-231.

Huebner, L. A., Royer, J. A., \& Moore, J. (1981). The assessment and remediation of dysfunctional stress in medical school. Journal of Medical Education, 56, 547-558.

Jepsen, D. A., \& Prediger, D. J. (1981). Dimensions of adolescent career development: A multi-instrument analysis. Journal of Vocational Behavior, 19, 350-368.

Markert, R. J. (1983). Change in specialty choice during medical school. Journal of Family Practice, 17, 295-300.

Osipow, S. H. (1980). Manual for the career decision scale. Columbus, OH: Marathon Consulting \& Press.

Osipow, S. H., Carney, C. G., \& Barak, A. (1976). A scale of educational-vocational undecidedness: A typological approach. Journal of Vocational Behavior, 9, 233-243.

Osipow, S. H., Carney, C. G., Winer, J. L., Yanico, B., \& Koschier, M. J. (1976). The career decision scale (3rd ed.). Columbus, $\mathrm{OH}$ : Marathon Consulting \& Press.

Palmiere, D. (1981). Specialization in medicine and nursing: Implications for social work. Health and Social Work, 6 (Suppl. to No. 4), 135-215.

Rogers, W. B., Jr., \& Westbrook, B. W. (1983). Measuring career indecision among college students: Toward a valid approach for counseling practitioners and researchers. Measurement and Evaluation in Guidance, 16, 78-85.

Savickas, M. L. (1984). Construction and validation of a physician career development inventory. Journal of Vocational Behavior, 25, 106-123.

Weisman, C. S., Levine, D. M., Steinwachs, D. N., \& Chase, G. A. (1980). Male and female career patterns: Specialty choices and graduate training. Journal of Medical Education, 55, 813-825.

Received April 25, 1985. 